\title{
In vitro and in vivo bacterial antifouling properties of phosphite plasma-treated silicone
}

\author{
Ebru Akdogan PhD \\ Researcher, Plasma Aided Bioengineering and Biotechnology Research \\ Group, Institute for Pure and Applied Sciences, Hacettepe University, \\ Ankara, Turkey (corresponding author: ebruakd@hacettepe.edu.tr) \\ Murat Demirbilek PhD \\ Researcher, Nanotechnology and Nanomedicine Division, Hacettepe \\ University, Ankara, Turkey \\ Yasin Sen PhD \\ Lecturer, Department of Tourism and Hotel Management, Faculty of \\ Business Administration, Atilim University, Ankara, Turkey \\ Mehmet Ali Onur PhD \\ Professor, Department of Biology, Faculty of Science, Hacettepe University, \\ Ankara, Turkey
}

\author{
Ozlem Kurt Azap PhD \\ Professor, Department of Clinical Microbiology and Infectious Disease, \\ Baskent University Faculty of Medicine, Ankara, Turkey \\ Erkin Sonmez PhD \\ Associate Professor, Department of Neurosurgery, Baskent University \\ Faculty of Medicine, Ankara, Turkey \\ Hasret Tolga Sirin PhD \\ Researcher, Bioengineering Division, Institute for Pure and Applied \\ Sciences, Hacettepe University, Ankara, Turkey \\ Mehmet Mutlu PhD \\ Professor, Plasma Aided Biomedical Research Group, Department of \\ Biomedical Engineering, Faculty of Engineering, TOBB University of \\ Economics and Technology, Ankara, Turkey
}

In order to improve their bacterial antifouling property, silicone surfaces were functionalized through the plasma polymerization (PP) technique using diethyl phosphite as the precursor. The functionalized surfaces were characterized using contact angle measurements, contact angle titration, Fourier transform infrared-attenuated total reflection spectroscopy and in vitro cytotoxicity assay. The amount of non-specific protein adsorption and the conformational changes of surface-adsorbed proteins were investigated. Antifouling properties of the surfaces were evaluated in vitro and in vivo. PP functionalization generated a hydrophilic and amphoteric surface with a very good protein and bacterial antifouling property and caused less conformational changes on the secondary structure of surface-adsorbed proteins. In in vivo conditions, no slime layer was formed around bacteria that adhered on the PPfunctionalized surface. It is concluded that the amphoteric nature of the PP-functionalized surface is the reason for the good antifouling property.

\section{Introduction}

Despite the advancements in surgical techniques and biomaterial design, implant-related infection is still one of the most frequent and severe complications associated with the use of biomaterials. ${ }^{1}$ Preventing the initial bacterial colonization on biomaterial surfaces is the key to reducing the prevalence of biomaterial-related infections. Amphotericity is known to play an important role in reducing non-specific bacterial adhesion and is usually generated by functionalizing the surface of a given biomaterial with desired bulk properties using polyampholytes (PAs), a method that can yield excellent non-fouling properties. ${ }^{2-4}$ PAs are synthesized through free-radical polymerization, anionic polymerization or group transfer polymerization and are incorporated into the surfaces by 'graft-from' or 'graft-to' methods. ${ }^{5-7}$ However, the synthesis and incorporation of PAs can be expensive and relatively complex, requiring intensive wet chemistry.

In this study, the use of the plasma polymerization (PP) method to generate amphoteric surfaces as a novel, feasible and straightforward surface functionalization approach has been investigated. The efficacy of the functionalized surfaces in reducing protein adsorption and bacterial adhesion was evaluated. Generation of amphoteric surfaces through the PP technique is seldom reported in the literature, and their performance as functional biomaterials has not been defined so far. Sardella et al. ${ }^{8}$ successfully generated amphoteric coatings by using a twomonomer system with acrylic acid and allylamine. Bryjak et al. ${ }^{9}$ showed that plasma treatment of polysulfone membranes with nitrogen $\left(\mathrm{N}_{2}\right)$ yielded amphoteric surfaces due to the many different groups created on the surface caused by the oxidative effect of the PP process. In a previous study, the authors showed that a phosphorus-containing precursor can be used to yield amphoteric surface properties by generating phosphorus acid and phosphine groups $\left(-\mathrm{PH}_{3}\right)$ on the surfaces. ${ }^{10}$ Most studies on protein adsorption and bacterial colonization on phosphated surfaces were conducted using bulk polymers containing phosphate as side groups, and most of these polymers had low mechanical strength in hydrated forms.

In this study, diethyl phosphite (DP) was used as the precursor to functionalize the surface of medical-grade silicone samples. Medical-grade silicone was chosen as the substrate because it is one of the most commonly used and most thoroughly tested materials in medical devices in the form of catheters, drains, shunts, small joint implants and aesthetic implants, ${ }^{11,12}$ and despite its relative inertness, it is still susceptible to bacterial fouling ${ }^{13,14}$ and can benefit from such surface functionalization. Functionalized materials were characterized in terms of surface 
hydrophilicity, surface amphotericity, surface chemistry and in vitro cytotoxicity. The extent of non-specific protein adsorption and the conformational changes of surface-adsorbed proteins were determined. Bacterial antifouling properties were evaluated in both in vitro and in vivo conditions.

\section{Experimental section}

\subsection{Plasma polymerization}

Small fragments of medical-grade silicone (Integra Life Sciences, USA) were cleaned sequentially by ultrasonication (J.P. Selecta, Abrera, Barcelona, Spain) in acetone, methanol (Merck, Darmstadt, Germany) and deionized water for $5 \mathrm{~min}$ and dried in a vacuum oven (Shel Lab, Oregon, USA) at $80^{\circ} \mathrm{C}$ for $1 \mathrm{~h}$. Silicone surfaces were modified in a radio-frequency (RF) (13.56 MHz) PP system (Diener Electronic, Nagold, Germany). Samples were placed in the plasma chamber, and the air in the chamber had been evacuated to reach $0 \cdot 10$ mbar pressure. The precursor, DP (98\%, Aldrich, Steinheim, Germany), was degassed by repeated freezing and thawing under vacuum four times using liquid nitrogen. ${ }^{15,16}$ Following degassing, the precursor was fed to the chamber; vapor was allowed to fill the reactor until the pressure in the reactor reached a level of 0.30 mbar. RF power was adjusted to $100 \mathrm{~W}$, and the substrates were exposed to glow discharge for $5 \mathrm{~min}$. At the end of the process, the system was fed with argon gas for $20 \mathrm{~min}$ to deactivate free radicals. The optimization of plasma conditions is reported elsewhere. ${ }^{17}$

\subsection{Contact angle titration}

The surface acid-base properties were determined using the contact angle (CA) titration method. ${ }^{9}$ Briefly, different concentrations of hydrochloric acid $(\mathrm{HCl})$ and sodium hydroxide $(\mathrm{NaOH})$ solutions were prepared in the $\mathrm{pH}$ range 1-14 in deionized water. The $\mathrm{pH}$ values of the solutions were recorded before use. Solution droplets of about $3 \mu$ l volumes were dropped onto the surfaces and recorded using a charge-coupled device (CCD) camera at $20^{\circ} \mathrm{C}$. At least five measurements at different points were taken for each surface. CAs were calculated using the computer software Wettability Pro Classic (version 2.0.0, Czech Republic). Surface apparent acidities (AAs) and surface apparent basicities (ABs) were calculated according to the method described by Bryjak et al. ${ }^{9}$ For the calculations, a flat, smooth polymer surface was considered and the roughness or chemical heterogeneity was neglected. Even if those assumptions were invalid, CA titration depends on the gradient of CA against the probe molecule concentration on the surface, and thus, adsorption is the dominant parameter. ${ }^{18}$

\subsection{CA measurements and surface energy calculations} The CA measurements were performed using the sessile drop technique. ${ }^{19}$ CAs of deionized water and $n$-octane on bare and PP-functionalized surfaces have been measured by dropping droplets of about $5 \mu \mathrm{l}$ in volume on the surfaces and recording the CAs using a $\mathrm{CCD}$ camera at $20^{\circ} \mathrm{C}$. CAs were calculated using the computer software Wettability Pro Classic. At least five measurements at different points were taken for each surface. Surface free energy (SFE) calculations were performed using the harmonic mean equation. ${ }^{20}$

\subsection{Fourier transform infrared-attenuated total reflection spectroscopy}

Fourier transform infrared (FTIR) analyses were performed using a PerkinElmer Spectrum 100 FTIR spectrophotometer equipped with an attenuated total reflectance (ATR) apparatus and a diamond crystal using a liquid-nitrogen-cooled mercury cadmium telluride detector at a resolution of $4 \mathrm{~cm}^{-1}$. For each sample, 512 scans were performed. The spectrum of the PP-treated surface was further processed by subtracting the bare silicone's spectrum from the spectrum of the modified surface.

\subsection{Scanning electron microscopy (SEM) imaging}

Environmental SEM (ESEM; Quanta 200 FEG model ESEM, FEI, USA) was used for the visualization of bacterial adhesion. Bacteria were fixed in a sterile glutaraldehyde $(50 \%$; AppliChem, Germany) solution containing $0 \cdot 5 \%$ (v/v) phosphatebuffered saline (PBS) for $15 \mathrm{~min}$ at ambient temperature. All samples were coated with a thin layer of gold (about $20 \mathrm{~nm}$ ) prior to imaging.

\subsection{Protein adhesion and conformation}

The effects of surface functionalization on the non-specific protein adsorption and on the secondary structure of surface-adsorbed proteins were evaluated. Bovine serum albumin (BSA) was chosen as the model protein since its secondary structure is widely investigated in the literature and it is very well established. ${ }^{21-23}$ Briefly, substrates were placed in a $10 \mathrm{ml}$ beaker containing BSA (lyophilized powder $\geq 98 \%$, Sigma-Aldrich, Germany) solution at $1 \mathrm{mg} / \mathrm{ml}$ concentration in PBS (pH 7.4) and were incubated in a shaking water bath (N-Biotek Inc., USA) at $37^{\circ} \mathrm{C}$ for $24 \mathrm{~h}$. The amount of BSA in the solution after $24 \mathrm{~h}$ was determined using an ultraviolet-visible spectrophotometer (PerkinElmer Lambda 25 spectrophotometer, USA) at $280 \mathrm{~nm}$.

The changes in the secondary structure of surface-adsorbed proteins were evaluated using FTIR-ATR spectroscopy. For this purpose, second-derivative and curve-fitting $(\mathrm{CF})$ procedures were performed. In the fitting procedure, the amide I band was treated to give a linear baseline between 1720 and $1580 \mathrm{~cm}^{-1}$. Fitting was performed assuming Gaussian band profiles. Peak positions were not fixed during fitting. ${ }^{24-27}$

\subsection{In vitro cytotoxicity}

A method adapted from the ISO 10993-5 indirect cytotoxicity standard (3-(4,5-dimethylthiazol-2-yl)-2,5-diphenyltetrazolium bromide (MTT) assay) was implemented using L929 mouse fibroblast cells. ${ }^{28}$ L929 cells were cultured as a monolayer in Dulbecco's modified Eagle's medium (Sigma-Aldrich, USA) supplemented with $10 \%$ fetal bovine serum (Biochrom, Germany) and $1 \%$ L-glutamine (Invitrogen, USA), together with 100 units $/ \mathrm{ml}$ penicillin (Invitrogen, USA) and $100 \mathrm{~g} / \mathrm{ml}$ streptomycin 
(Invitrogen, USA). The medium was replaced once in every $3 \mathrm{~d}$, and the cultures were maintained at $37^{\circ} \mathrm{C}$ in an air atmosphere containing 5\% carbon dioxide $\left(\mathrm{CO}_{2}\right)$. When the cells reached $80 \%$ confluence, they were trypsinized with $0 \cdot 25 \%$ trypsin containing $1 \mathrm{mM}$ ethylenediaminetetraacetic acid (Invitrogen, USA) and counted by using a hemocytometer (Hausser Scientific, USA) prior to use. ${ }^{29}$ Samples were prewashed with $70 \%$ ethanol for $1 \mathrm{~h}$ and sterile PBS buffer and with the culture medium sequentially. After washing steps, samples were then incubated at $37^{\circ} \mathrm{C}$ in fresh cell culture medium for $72 \mathrm{~h}$ for the preparation of the extraction media $(n=8)$. The extraction ratio was $0 \cdot 2 \mathrm{~g}$ sample $/ \mathrm{ml}$ cell culture medium. L929 cells were seeded in empty wells of a 96-well tissue-culture polystyrene (PS) plate (Corning, USA) at $7 \times 10^{3}$ cells $/ \mathrm{ml}$ and incubated overnight. The medium was then replaced with the extraction medium for each type of the specimens, and the cells were further incubated. After $24 \mathrm{~h}$, the extraction medium was removed. One hundred microliters of fresh medium and $13 \mu \mathrm{l}$ of MTT solution $(5 \mu \mathrm{g} / \mathrm{ml}$, diluted with Roswell Park Memorial Institute 1640 medium without phenol red) were pipetted to the each well. Incubation was allowed for another $4 \mathrm{~h}$ in the dark at $37^{\circ} \mathrm{C}$. Media were removed, and $100 \mu \mathrm{l} /$ well isopropanol-hydrochloric acid (absolute isopropanol containing 0.04 M hydrochloric acid) solution was added to dissolve formazan crystals. The wells were read at $570 \mathrm{~nm}$ on Asys Expert Plus enzyme-linked immunosorbent assay reader, and the percentage of cell viability was calculated. The viability of the cells cultured with fresh serum-free medium was used as the control. Cell viability was defined as $100 \%$ for the MTT assay control.

\subsection{In vitro bacterial adhesion}

In vitro bacterial adhesion tests were conducted using a slimeforming Staphylococcus epidermidis strain (American Type Culture Collection 35983), which is known to be one of the major causes of postsurgery biomaterial-associated infections. ${ }^{30}$ Samples $(n=5)$ were incubated in brain heart infusion broth (Lab M, UK) with suspension of $10^{8}$ colony-forming units (CFU)/ml $S$. epidermidis, after which they were removed from the broth culture, rinsed with $9 \mathrm{ml}$ sterile $0.85 \%(\mathrm{w} / \mathrm{v})$ saline solution two times to remove loosely attached bacteria. Samples were then placed in $0 \cdot 85 \%(\mathrm{w} / \mathrm{v})$ saline solution containing $0 \cdot 1 \%(\mathrm{v} / \mathrm{v})$ Tween 80 and vortexed for $2 \mathrm{~min}$. One milliliter of the suspension was inoculated onto brain heart infusion agar, diluted as necessary and incubated at $37^{\circ} \mathrm{C}$ for $24 \mathrm{~h}$. The resulting colonies were counted and reported. ${ }^{31}$

\subsection{In vivo bacterial adhesion}

The following procedures were applied after receiving permission/approval from the Animal Ethical Committee of Hacettepe University, Ankara, Turkey (approval number: B.30.2.HAC.0.001.00.05/5; approval date: 3 March 2010). Bare and PP-functionalized samples were preseeded with $10^{8} \mathrm{CFU} / \mathrm{ml}$ S. epidermidis before operation. After $2 \mathrm{~h}$ of incubation at $37^{\circ} \mathrm{C}$, samples were washed with sterile physiological saline solution. Twelve-month-old Sprague-Dawley rats $(n=10,419 \pm 12 \mathrm{~g})$ were maintained in plastic cages at the laboratory under clean conventional conditions and fed standard rat chow and water ad libitum. The animals were allowed to acclimatize to the laboratory conditions for 1 week prior to the operation and were allowed to move freely before and after the operation. General anesthesia was continued by injecting $45 \mathrm{mg} / \mathrm{kg}$ of ketamine hydrochloride and $5 \mathrm{mg} / \mathrm{kg}$ of xylazine intramuscularly. Abdominal regions of rats were shaved and cleaned with iodine solution. Two-centimeter-deep pockets were opened on their abdominal region through $1 \mathrm{~cm}$ incisions. Preseeded samples were inserted into these pockets, and the incisions were sutured. At least one sample from each group was implanted into each rat. After the operation, rats were maintained in separate cages. After $72 \mathrm{~h}$, rats were scarified with a high dose of anesthetics (ether) and implanted samples were removed and transferred into sterile physiological saline solution containing $0 \cdot 1 \%$ Tween 80 and were cultured immediately. A $72 \mathrm{~h}$ of implantation time was chosen because the critical time for bacterial colonization leading to biofilm formation occurs in the first $72 \mathrm{~h}^{32}$

\subsection{Statistical analysis}

Statistical analysis was performed using one-way analysis of variance (Anova) with SPSS 13.0 software (SPSS, USA). $p$ values of less than $0.05(p \leq 0.05)$ were considered statistically significant. For bacterial adhesion tests, the results were evaluated using both one-way Anova and Tukey's test.

\section{Results and discussion}

\subsection{CA measurements, surface energy calculations and CA titration}

Water CA values of bare silicone and PP-functionalized surfaces were $98 \cdot 0 \pm 3 \cdot 0$ and $37 \cdot 1 \pm 5 \cdot 2^{\circ}$, respectively. The SFE values of bare and PP-functionalized samples were calculated as $27 \cdot 0 \pm 1 \cdot 2$ and $59.8 \pm 3 \cdot 1 \mathrm{~mJ} / \mathrm{m}^{2}$, respectively. The SFE value of bare silicone was close to the SFE values previously reported in the literature as being between 20 and $33 \mathrm{~mJ} / \mathrm{m}^{2}$. An increase in the SFE after PP functionalization has been observed.

The surface acid/base properties of the materials have been determined using the CA titration method developed by Bryjak et al. ${ }^{9}$ based on the work of Fowkes et al. ${ }^{18} \mathrm{CA}$ titration curves of bare and PP-functionalized silicone surfaces are given in Figures 1(a) and 1(b). The surface $\mathrm{AA}$ and $\mathrm{AB}$ values of the surfaces were calculated using the corresponding CA titration curves (Table 1). The surface of bare silicone was slightly basic with a surface $\mathrm{AB}$ of $0 \cdot 12 \mu \mathrm{mol} / \mathrm{m}^{2}$. On the other hand, the PPfunctionalized silicone surface showed an amphoteric property with surface $\mathrm{AA}$ and $\mathrm{AB}$ values of 1.52 and $1.70 \mu \mathrm{mol} / \mathrm{m}^{2}$, respectively (Figures 1(a) and 1(b)). CA titration data suggest that after plasma modification, both acidic and basic groups (proton donor and acceptor groups) were present on the surface. The basic property of bare silicone cannot be solely responsible for the surface basicity of functionalized samples because the amount of the surface $\mathrm{AB}$ increased from 0.12 to $1.70 \mu \mathrm{mol} / \mathrm{m}^{2}$ after functionalization. Functionalization with DP resulted in an amphoteric and hydrophilic $\left(\theta<90^{\circ}\right)$ surface. 


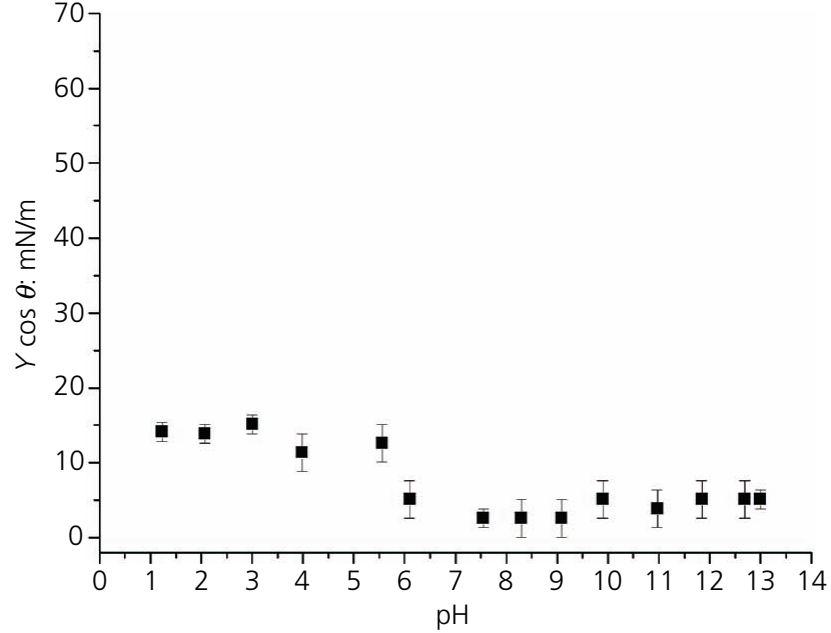

(a)

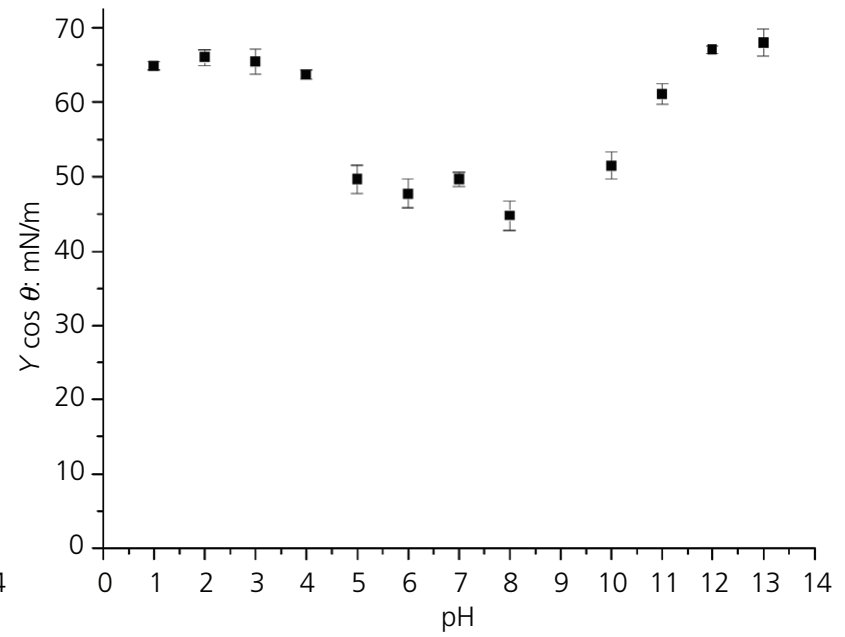

(b)

Figure 1. CA titration of (a) bare silicone surface and (b) PP-functionalized surface. $Y$, surface tension; $\theta$, contact angle of the probe on the surface

Table 1. Inflection points and surface AAs and ABs of bare and PP-functionalized silicone surfaces

\begin{tabular}{lccc|} 
Surface & pH region & Inflection point & $\begin{array}{c}\text { AA or AB: } \\
\boldsymbol{\mu m o l} / \mathbf{m}^{2}\end{array}$ \\
\hline Bare silicone & $<7.0$ & $\mathrm{pH} 4.84$ & 0.12 \\
PP-functionalized & $<7.0$ & $\mathrm{pH} 4.53$ & 1.52 \\
silicone & $>7.0$ & $\mathrm{pOH} 10.50$ & 1.70
\end{tabular}

\subsection{FTIR-ATR spectroscopy}

The FTIR-ATR spectrum of the PP-functionalized surface is given in Figure 2. The broad peak observed at around $3250 \mathrm{~cm}^{-1}$ is attributed to the stretching vibrations of $\mathrm{Si}-\mathrm{OH}$ groups that were possibly formed due to the oxidation effect of the PP process. ${ }^{33}$ Peaks observed at around 2958, 2935, 2873 and $1703 \mathrm{~cm}^{-1}$ were attributed to the $\mathrm{C}-\mathrm{H}$ stretching vibrations. ${ }^{22,34,35}$ Peaks observed between 2700 and $2100 \mathrm{~cm}^{-1}$ were attributed to the acidic phosphorus acid $\mathrm{O}-\mathrm{H}$ stretching vibrations. $\mathrm{P}-\mathrm{H}$ stretching vibrations of basic phosphine groups were observed at 2028 and $807 \mathrm{~cm}^{-1} .{ }^{35}$ Peaks observed at 1975 and $667 \mathrm{~cm}^{-1}$ were attributed to $\mathrm{C}-\mathrm{H}$ bending vibrations, while the peak around $1500 \mathrm{~cm}^{-1}$ was attributed to the $\mathrm{C}-\mathrm{O}$ stretching vibration. $\mathrm{P}=\mathrm{O}$ stretching vibrations were observed around 1380 and $1234 \mathrm{~cm}^{-1}$, while the $\mathrm{P}-\mathrm{O}-\mathrm{C}$ stretching vibration was observed at $1054 \mathrm{~cm}^{-1} \cdot 22,34,35$ Although the phosphorus acid $\mathrm{O}-\mathrm{H}$ and $\mathrm{P}-\mathrm{H}$ groups were not present in the DP monomer, they were present on the surface after plasma functionalization, which is probably due to the random breaking down and reformation of new bonds during the plasma process. FTIR data also indicate that after plasma modification, both acidic and basic groups (proton donor and acceptor groups) were present on the surface. The surface acidic moieties were possibly formed by the surface phosphorus acid - $\mathrm{OH}$ groups. The surface basicity is believed to be caused by the phosphine groups $\left(-\mathrm{PH}_{3}\right)^{36}$
The surface chemistry after plasma modification is highly dependent on plasma conditions, substrate properties and the precursor. $^{37}$ For example, Siow et al. ${ }^{38}$ used triisopropyl phosphite and DP to coat the surfaces of silicon wafers and fluorinated ethylene propylene using a custom-made plasma reactor. Although both this report and the work of Siow et al. ${ }^{38}$ showed monomer fragmentation leading to subsequent variety in the surface composition, their plasma conditions allowed them to generate phosphate and polyphosphate groups on the surfaces, while the conditions reported in this paper lead to the formation of phosphine and phosphorus acid groups.

\subsection{Protein adhesion and conformational changes}

The amounts of BSA adsorbed on bare silicone and PPfunctionalized silicone were $494 \cdot 0 \pm 12 \cdot 0$ and $36 \cdot 0 \pm 3 \cdot 0 \mu \mathrm{g} / \mathrm{cm}^{2}$, respectively. The amount of BSA adsorption was reduced by $92 \cdot 7 \%$ after surface functionalization.

When surface-adsorbed proteins undergo conformational changes, the adhesion becomes irreversible and the adhered layer of proteins induces more adsorption of organic matter from the environment that surrounds the material. Thus, it is also important to determine the extent of conformational changes occurring on a protein's structure upon its adsorption. The conformational changes of BSA adsorbed on bare and PP-functionalized silicone surfaces were investigated using FTIR-ATR. The amide I/II intensity ratios and components of the amide I band of surfaceadsorbed BSA are given in Figures 3 and 4.

The amide I band $\left(1700-1600 \mathrm{~cm}^{-1}\right)$ represents about $80 \%$ of the $\mathrm{C}=\mathrm{O}$ stretching vibration of the amide group. The exact wave number of this vibration depends on the nature of hydrogen bonding and the particular secondary structure of the protein being considered, and this structure consists of a number of 


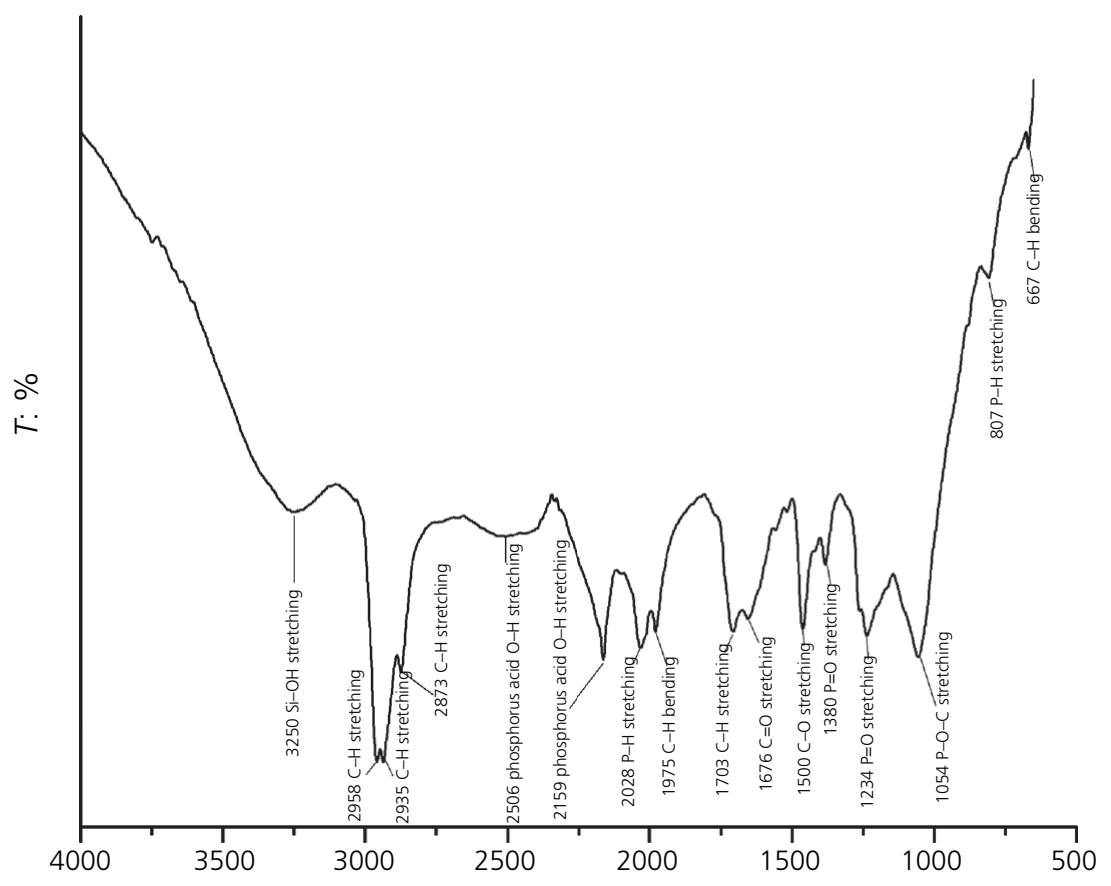

Figure 2. FTIR-ATR spectrum of PP-functionalized surface

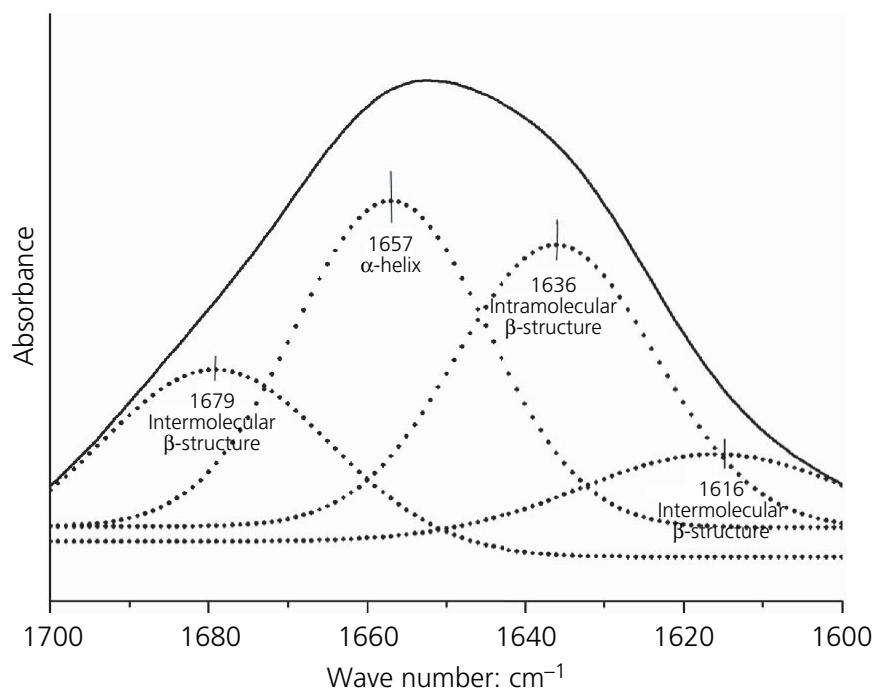

(a)

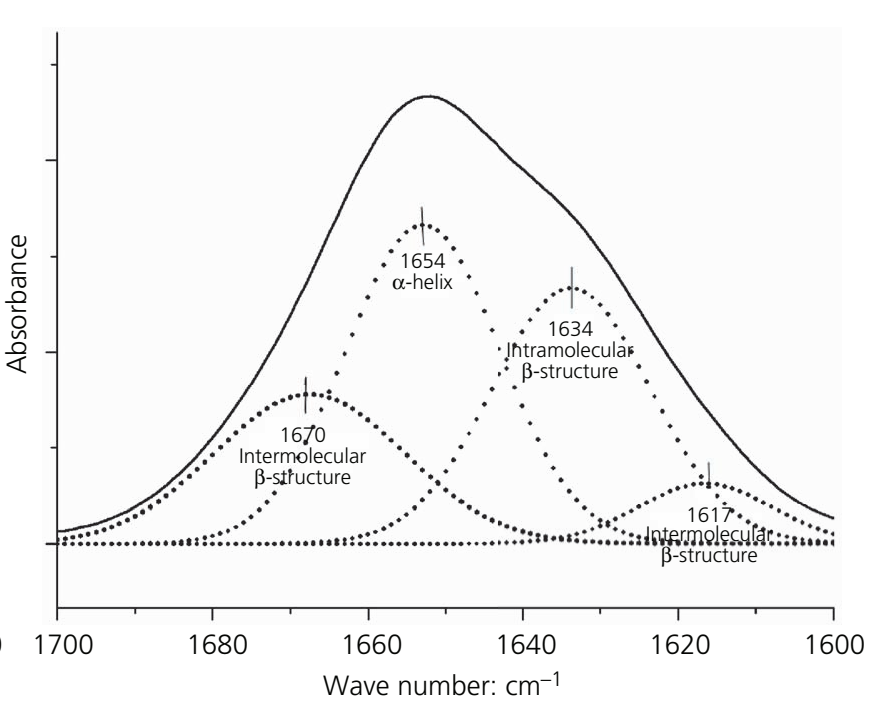

(b)

Figure 3. Amide I band fitted with component peaks of BSA adsorbed on (a) bare silicone surface and (b) PP-functionalized surface

overlapping component bands such as helices, $\beta$-structures, turns and random structures. The percentage of these components can be determined using CF procedures with the assumption that the effective absorptivities of all components are equal. ${ }^{22,34,39,40}$ In Figure 3, peaks observed between 1695 and 1670 and 1625 and $1610 \mathrm{~cm}^{-1}$ are assigned to the intermolecular $\beta$-structure; between 1690 and 1680 and 1640 and $1630 \mathrm{~cm}^{-1}$, to the intramolecular $\beta$-structure; between 1666 and $1659 \mathrm{~cm}^{-1}$, to the 'three-turn' helix; between 1657 and $1648 \mathrm{~cm}^{-1}$, to the $\alpha$-helix; and between 1645 and $1640 \mathrm{~cm}^{-1}$ to the random coil structure. ${ }^{22}$

The amide II band $\left(1600-1500 \mathrm{~cm}^{-1}\right)$ consists of $\mathrm{N}-\mathrm{H}$ bending, with some $\mathrm{C}-\mathrm{N}$ stretching, and its exact wave number also depends on the nature of hydrogen bonding and the particular secondary structure of the protein being considered. The amide II band is less sensitive to the conformational changes in the protein 


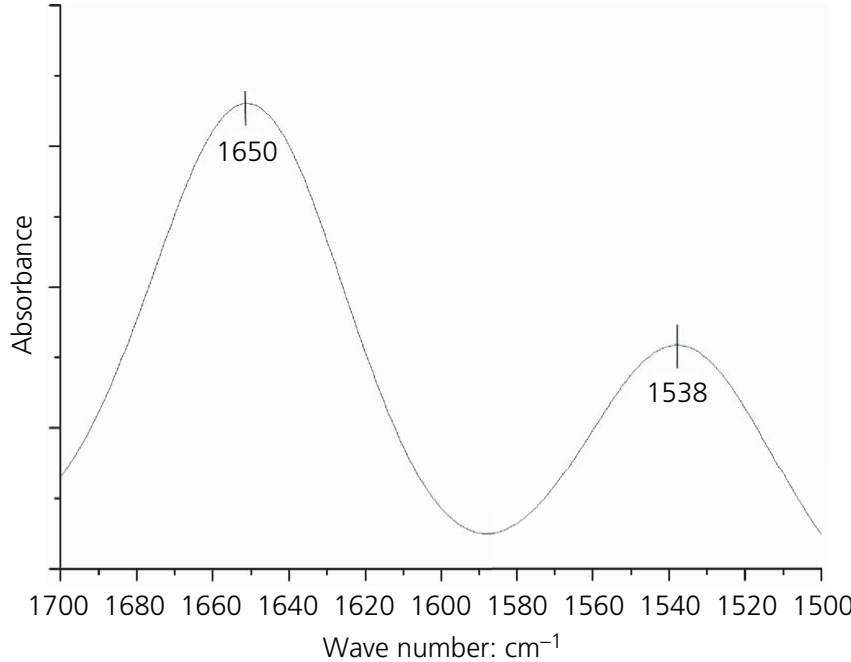

(a)

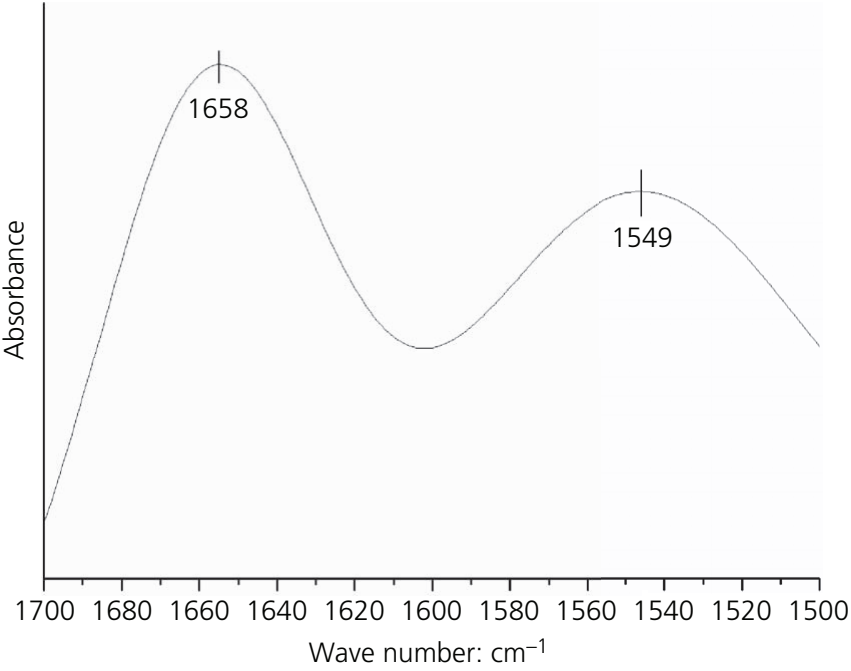

(b)

Figure 4. Amide I and amide II bands of BSA adsorbed on (a) bare silicone surface and (b) PP-functionalized surface

structure; however, the amide I/II intensity ratio can be used to identify orientation changes in the protein structure. ${ }^{22,35}$ Amide I and amide II maxima, amide I/II ratios and the $\alpha$-helix content of BSA adsorbed on surfaces are given in Table 1. The amide I maximum of bare silicone surface shifted from $1650 \pm 2$ to 1658 $\pm 2 \mathrm{~cm}^{-1}$ for the PP-functionalized surface. The maxima of the amide I bands indicate a higher $\alpha$-helix content for BSA that is adsorbed on the PP-functionalized surface. The $\alpha$-helix content of BSA adsorbed on the surfaces was calculated as the ratio of the $\alpha$-helix peak area to the total amide I peak area. The $\alpha$-helix contents of BSA adsorbed on bare and PP-functionalized silicone surfaces were found to be $33 \cdot 0 \pm 5 \cdot 0$ and $45 \cdot 0 \pm 3 \cdot 0 \%$, respectively. It should be noted that BSA in solution has an $\alpha$-helix content of about $55 \%$ and only a small amount of $\beta$-sheets. ${ }^{24,40}$ The $\alpha$-helix content of $45 \cdot 3 \%$ upon adsorption on the PP-functionalized surface suggests that BSA is keeping its structure much closer to its original level of $55 \%$.

The amide II maximum for BSA adsorbed on the bare silicone surface was $1538 \pm 2 \mathrm{~cm}^{-1}$, while that for BSA adsorbed on the PP-functionalized surface was $1549 \pm 3 \mathrm{~cm}^{-1}$. The amide I/II intensity ratio, which was $1.33 \pm 0.01$ for the bare silicone surface, increased to $1.45 \pm 0.01$ for the PP-functionalized surface. In its native form, BSA in solution has an amide I/II ratio of 1.82 and is reported to decrease to about 1.07 after heat denaturation. ${ }^{41,42}$ The decrease in the amide I/II ratio indicates loss in the $\alpha$-helix content, which is more pronounced for BSA adsorbed on the bare silicone surface than that adsorbed on the PP-functionalized surface, suggesting that the secondary structure of BSA adsorbed on the bare silicone surface changes to a greater extent. There is also a significant shift in the position of amide I maxima depending on the amide I/II ratio. As the amide I/II ratio decreases for the BSA adsorbed on the silicone surface, the amide I maximum shifts to $1650 \mathrm{~cm}^{-1}$, and as this ratio decreases for PP-functionalized surfaces, the amide I maximum shifts to around $1658 \mathrm{~cm}^{-1}$, again indicating changes in the helix content. $^{40,42}$ These results are also consistent with the $\alpha$-helix percentages calculated from the amide I band.

The amount of BSA adsorbed on the surface of PP-functionalized samples were $92 \cdot 7 \%$ less than BSA adsorbed on the bare silicone surface. In addition, BSA adsorbed on the PP-functionalized surface maintained its secondary structure at a greater extent compared to BSA adsorbed on the bare silicone surface.

\subsection{In vitro cytotoxicity}

The cytotoxicity of silicone after surface functionalization has been investigated before proceeding with the in vitro tests. It is known that medical-grade silicone is a biocompatible, noncytotoxic material. ${ }^{43}$ Results showed that there is no significant difference between the viability of cells exposed to the extraction medium of PP-functionalized silicone $(100 \cdot 78 \% \pm 0 \cdot 03 \%)$ and control group (100\%) $(p>0.05)$ (Figure 5). Cells exposed to the extraction medium of bare silicone had a slightly lower viability $(93 \cdot 72 \% \pm 0 \cdot 04 \%)$ than the control group $(p \leq 0 \cdot 05)$.

\subsection{In vitro bacterial adhesion}

It is widely recognized that protein adsorption is an initiating factor for bacterial adhesion since bacterial receptors recognize surface-adhered proteins, and it is usually assumed that bacterial adhesion can be reduced by preventing protein adsorption. Although this assumption is partly correct, these two aspects should be evaluated separately. ${ }^{44,45}$ First, bacteria can adhere to organic-matter-conditioning surfaces other than proteins. Second, bacteria can synthesize surface-conditioning extracellular matrix components (slime) such as enzymes, lipopolysaccharides, biosurfactants and peptidoglycans to promote adhesion. ${ }^{45-49}$ In order to include the effect of both parameters, a slime-forming 


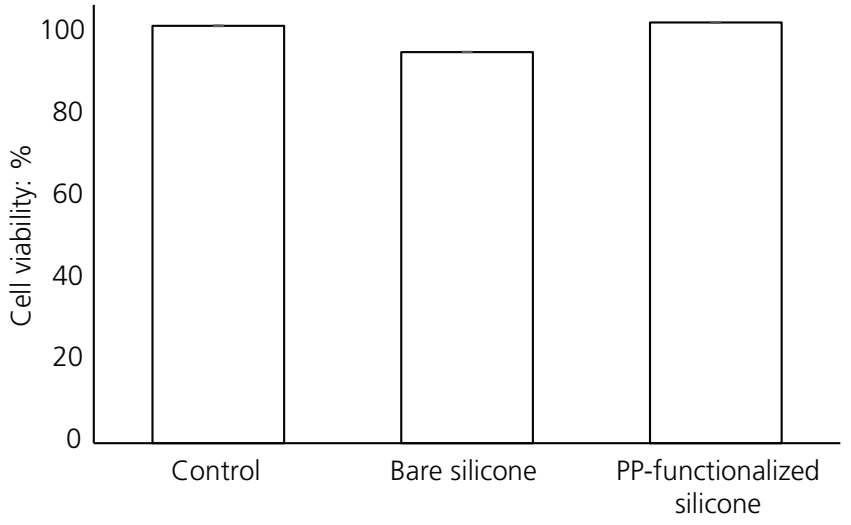

Figure 5. Cytotoxicity evaluation of silicone and PP-functionalized silicone

species of $S$. epidermidis was used and the adhesion experiments were carried out in a culture medium that is rich in various organic matter. The numbers of $S$. epidermidis that adhered onto the surface of bare and PP-functionalized silicone were $2.64 \times 10^{4}$ and $3.43 \times 10^{2} \mathrm{CFU} / \mathrm{cm}^{2}$, respectively. Surface functionalization caused $98 \cdot 70 \%$ reduction in bacterial adhesion $(p<0 \cdot 05)$. SEM images (Figure 6) show a high bacterial load on the bare silicone surface and a lower bacterial load on the PP-functionalized surfaces. Deformation observed on some bacterial cells is probably due to the charging of cell walls in the ESEM environment.

When compared with the results of in vitro adhesion studies reported in the literature, the $98 \cdot 70 \%$ reduction in the in vitro adhesion of $S$. epidermidis reported in this paper can be regarded as a promising result. Various methods have been developed in order to prevent bacterial adhesion on biomaterial surfaces such as antibiotic incorporation in the form of impregnation or surface attachment, ${ }^{50-54}$ generation of bacterial antifouling or bacteriarepelling surfaces, ${ }^{55-59}$ the use of quorum-sensing antagonists ${ }^{60-62}$ and incorporation of silver. ${ }^{63-65}$ The efficacies of these methods have been extensively investigated in in vitro conditions with the reduction in surface bacterial adhesion reported as being between 60 and $99 \%{ }^{62,66-74}$ For example, the adhesion of S. epidermidis on a titanium surface with bioactive water-soluble copolymers bearing sulfonate functions has been reported to be reduced by $68 \%$ compared to that for the untreated surface, ${ }^{66}$ while modification of PS with hyaluronic acid and alginic acid yielded over $99 \%$ reduction in the adhesion of $S$. epidermidis compared to that for the untreated surface. ${ }^{75}$ The use of zwitterions and PAs for the reduction of bacterial adhesion is a relatively new strategy, and there are fewer reports on their efficacy. ${ }^{76,77} \mathrm{Mi}$ et al. ${ }^{77}$ reported that the number of $S$. epidermidis that adhered onto a mixed-charge copolymer surface composed of positively charged quaternary amine and negatively charged carboxylic acid monomers can be significantly reduced and the adhered bacteria could be easily removed by changing the environmental $\mathrm{pH}$ conditions. Cheng et al. $^{73}$ reported that long-chain zwitterionic poly(sulfobetaine methacrylate) (polySBMA) surfaces grafted through atom transfer radical polymerization can reduce the adhesion of $S$. epidermidis by $92 \%$ relative to that for a bare glass surface. Good antifouling performance $(<5 \%$ coverage of Escherichia coli and Staphylococcus aureus) of thin polymeric films composed of polySBMA brushes controlled through copolymerizing SBMA and methacryloyloxyethyltrimethyl ammonium chloride was reported by Guo et al. ${ }^{70}$ Smith et al. ${ }^{78}$

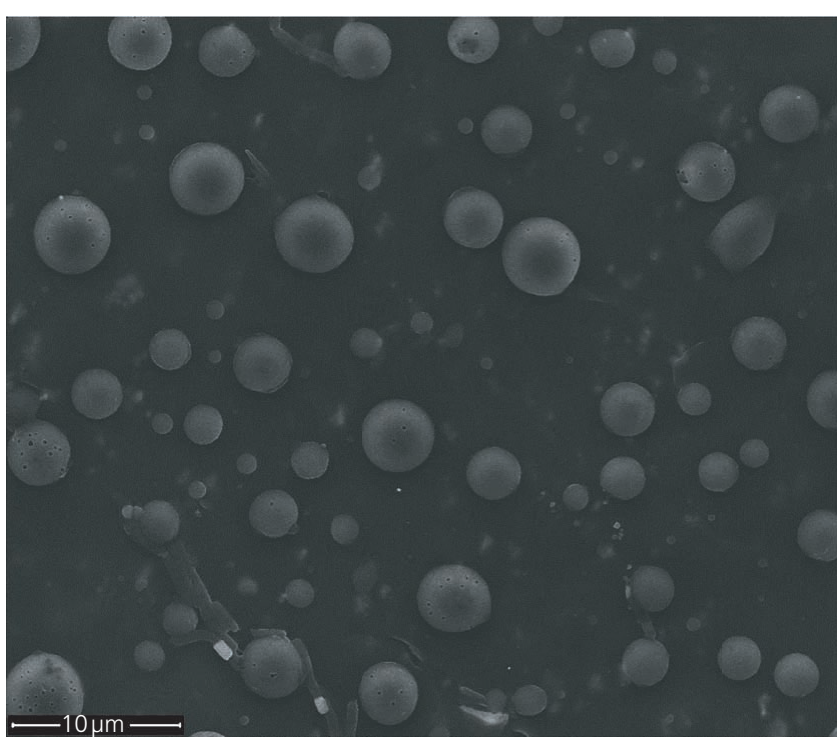

(a)

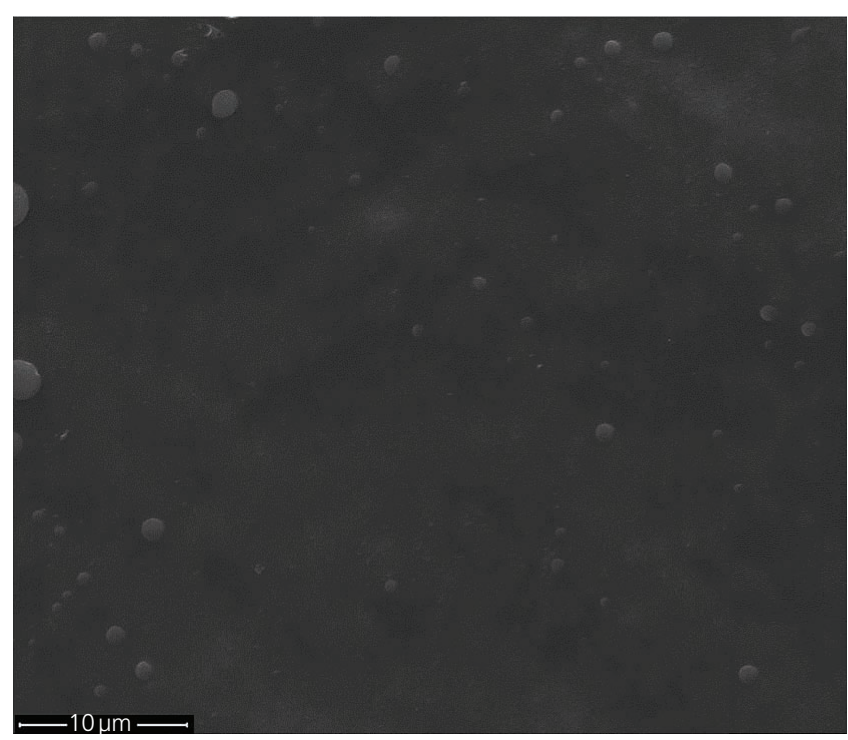

(b)

Figure 6. SEM images of S. epidermidis on (a) bare silicone surface and (b) PP-functionalized surface 
investigated the effect of polysulfobetaine (polySB) surface modification of peripherally inserted central catheters (PICCs), and they reported 97 and $99.9 \%$ reduction in the adhesion of E. coli and S. aureus compared to unmodified PICCs.

\subsection{In vivo bacterial adhesion}

The numbers of $S$. epidermidis found on the surface of the samples removed from rats were 112.71 and $10 \cdot 33 \mathrm{CFU} / \mathrm{cm}^{2}$ for bare and PP-functionalized samples, respectively. The number of adhered S. epidermidis was reduced by $90 \cdot 83 \%$ for the PPfunctionalized sample $(p<0.05)$. The reduction of in vivo bacterial adhesion for various surface modification strategies is reported to be between 70 and $99 \%{ }^{50,78-82}$ For example, Smith et al..$^{78}$ used a rabbit model to investigate the effect of zwitterionic polySB surface modification of PICCs, and they reported 97\% fewer bacteria isolated from polySB-modified samples compared to unmodified samples. The in vivo antimicrobial activity of covalently coupled quaternary ammonium silane (QAS) coatings on silicone rubber in albino Oxford rats was reported. ${ }^{80}$ Preoperative seeding with $S$. aureus resulted in infection of seven out of eight bare silicone implants compared to one out of eight QAS-coated implants. Postoperative seeding with $S$. aureus resulted in similar infection incidences on both implant types, while the number of adhering bacteria was reduced by $70 \%$ on QAS-coated silicone rubber. ${ }^{80}$ Dacron grafts coated with RNAIIIinhibiting peptide were reported to reduce the adhesion of S. epidermidis up to $99 \%{ }^{79}$ Although surfaces that prevent biofilm formation at early stages are desirable in clinical settings, in vivo efficacy of many of the attempts of creating such surfaces is difficult to achieve due to the complex interactions between surfaces, bacteria and host. ${ }^{83}$ The results reported in this paper can be concluded as being efficient in comparison to the results reported in the literature..$^{50,78-82}$

SEM images of sample surfaces removed from rats show biofilm formation on bare silicone surface (Figure 7). A mucosal structure was formed around bacterial cells, and some cells were buried into the biofilm structure. On the surface of PP-functionalized samples, bacterial cells were less frequent and no slime formation was observed. The crystalline-like structure is thought to be salt crystals condensed on the surface, probably due to the plasma process. A similar observation was reported by Kockro et al. ${ }^{50}$ where SEM images of silicone catheters removed from animals showed $S$. epidermidis colonies seeming to be embedded in a smooth slime matrix. Since slime formation directly leads to biofilm formation, the ability of PP-functionalized surfaces to prevent slime formation is very important to prevent biofilm formation further.

Surface modifications can limit both the amount of nonspecific protein adsorption and the changes in conformation of surface-adsorbed proteins by altering surface properties such as hydrophilicity/hydrophobicity and surface charge density. ${ }^{7,24,39,40,84,85}$ The non-fouling properties of PPfunctionalized surface are attributed to its amphotericity. The SFE of PP-functionalized surface was calculated as $59 \cdot 8 \pm 3 \cdot 1 \mathrm{~mJ} / \mathrm{m}^{2}$. According to the Baier curve which shows the correlation between SFE and antibiofouling properties, an SFE between 20 and $30 \mathrm{~mJ} / \mathrm{m}^{2}$ is regarded as antibiofouling. ${ }^{56,86}$ The PPfunctionalized surface has an SFE value out of this interval yet showed better antifouling property than the silicone surface with an SFE value of $27 \cdot 0 \pm 1 \cdot 2 \mathrm{~mJ} / \mathrm{m}^{2}$. The amphotericity of the

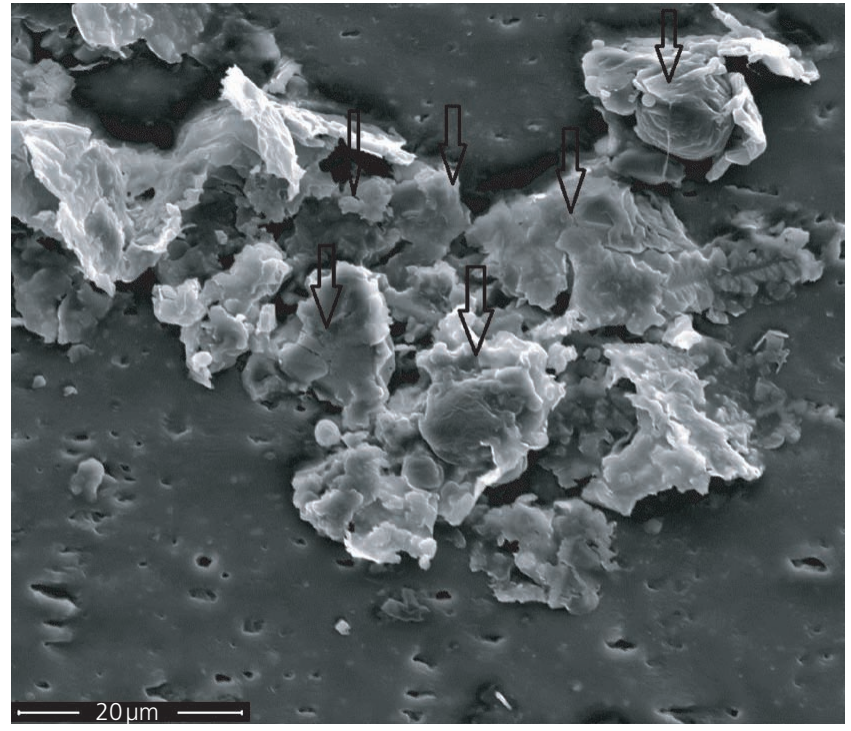

(a)

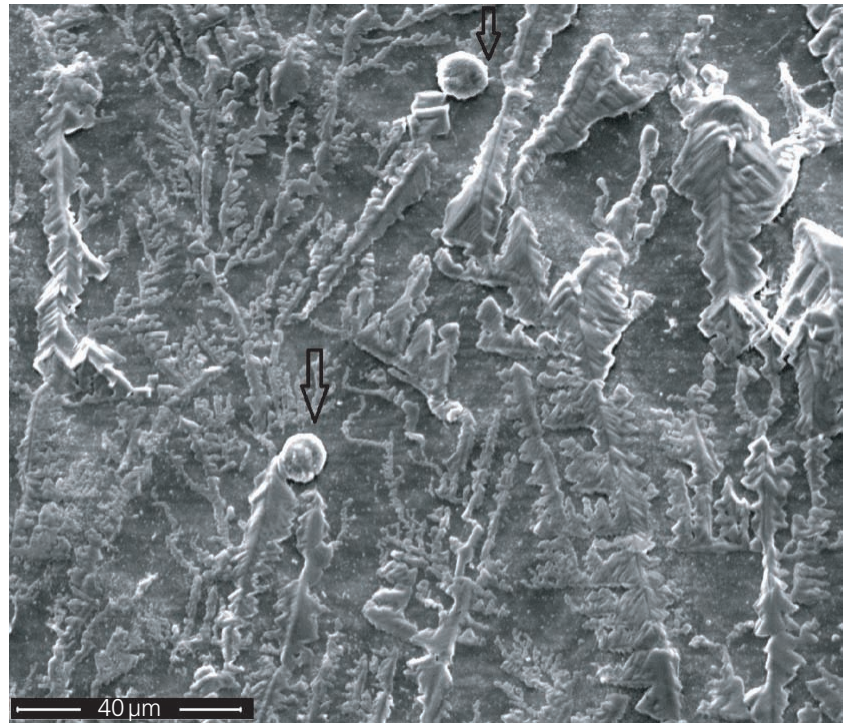

(b)

Figure 7. SEM images of S. epidermidis on (a) bare silicone surface removed from rats and (b) PP-functionalized surface removed from rats 
surface could be a possible explanation for the reduced bacterial adhesion. Zwitterionic surfaces with good antifouling properties are shown to have a surface energy around $70 \mathrm{~mJ} / \mathrm{m}^{2}$, a value which is very close to that of water. ${ }^{70}$ The higher surface energy reported for the zwitterionic materials when compared to the surface energy of polyethylene glycol $\left(43-46 \mathrm{~mJ} / \mathrm{m}^{2}\right)$ points to the effect of a higher hydrophilicity of zwitterions. ${ }^{87}$ In the presence of low-molecular-weight salts, PAs in their isoelectric state undergo swelling and result in high water incorporation. ${ }^{88}$ This swollen state is assumed to prevent undesired conformational changes in surface-adhered proteins. The hydrophobic interactions between protein molecules and cell membranes are also prevented by shielding the hydrophobic cores produced upon the perturbation of the native state of biomolecules by way of hydrophilic shells, thus hampering further conformational transitions. ${ }^{88}$ When the ratio between positive and negative charges is optimized to be around $1: 1$, which was around 0.9 for the PP-functionalized surface, PAs show excellent non-fouling properties due to the nanometer-scale homogeneous mixture of different charged groups. ${ }^{6}$ However, more investigations should be performed on the interfacial free energies, surface charge distribution and water incorporation to gain insights on the complex interaction between the functionalized surface and bacterial cells.

\section{Conclusion}

In the presented study, a medical-grade silicone surface was modified using the PP technique to yield an amphoteric surface using a single precursor, DP. The functionalized surface showed very good bacterial and protein antifouling properties. PP functionalization caused less conformational changes in the secondary structure of BSA adsorbed its surface. The amount of proteins adsorbed on functionalized surfaces was reduced by $92 \cdot 7 \%$. In vitro cytotoxicity results showed that PP-functionalized silicone was non-toxic to L929 cells. Functionalization with DP caused a $98 \cdot 70 \%$ reduction in $S$. epidermidis adhesion in vitro and $90 \cdot 83 \%$ reduction in vivo. It can be concluded that PP DP functionalization can be a promising method for the generation of biomaterials with bacterial antifouling properties. The effect of plasma-generated amphoteric surface property on bacterial adhesion and conformational transitions of surface-adsorbed proteins are also reported for the first time. In vivo testing is one of the most crucial steps in the research and development of biomaterials; often, new materials cannot be further tested or marketed without proving their efficacy and safety in animal models. The challenge is in the establishment of reliable correlations between the results of in vitro and in vivo studies. ${ }^{89}$ Although there are many reports on the in vitro evaluation of bacterial antifouling surfaces, there are a limited number of reports that assess their in vivo efficacy. Most of the antimicrobial coating approaches reported in the literature either fail in testing or cannot reach the status of in vivo animal (preclinical) experiments and the subsequent in vivo human (clinical) testing phase. ${ }^{89}$ Thus, findings related to the in vivo performance of a new material are believed to contribute to the research efforts in the field. Hence, the authors believe that this study can further contribute to the research on non-fouling biomaterials.

\section{Acknowledgements}

This research is partly supported by the Turkish Ministry of Industry and Technology (Project Number 0035.STZ.2009-1) and Deltamed Life Sciences and Plasma Technologies R\&D Inc. SEM imaging was performed in Unam - Institute of Materials Science and Nanotechnology.

\section{REFERENCES}

1. Arciola $C R$, Campoccia $D$ and Montanaro $L$ (2018) Implant infections: adhesion, biofilm formation and immune evasion. Nature Reviews Microbiology 16(7): 397-409.

2. Zhi Z, Su Y, Xi Y et al. (2017) Dual-functional polyethylene glycol- $b$ polyhexanide surface coating with in vitro and in vivo antimicrobial and antifouling activities. ACS Applied Materials \& Interfaces 9(12): 10383-10397.

3. Bernards MT, Cheng G, Zhang Z, Chen S and Jiang S (2008) Nonfouling polymer brushes via surface-initiated, two-component atom transfer radical polymerization. Macromolecules 41(12): 4216-4219.

4. Chen S, Li L, Zhao C and Zheng J (2010) Surface hydration: principles and applications toward low-fouling/nonfouling biomaterials. Polymer 51(23): 5283-5293.

5. Lowe AB and McCormick CL (2002) Synthesis and solution properties of zwitterionic polymers. Chemical Reviews 102(11): 4177-4190.

6. Li G, Xue H, Gao C, Zhang F and Jiang S (2009) Nonfouling polyampholytes from an ion-pair comonomer with biomimetic adhesive groups. Macromolecules 43(1): 14-16.

7. Chang Y, Shu SH, Shih YJ et al. (2010) Hemocompatible mixedcharge copolymer brushes of pseudozwitterionic surfaces resistant to nonspecific plasma protein fouling. Langmuir 26(5): 3522-3530.

8. Sardella E, Favia P, Dilonardo E, Petrone L and d'Agostino R (2007) PE-CVD of acid/base coatings from acrylic acid and allylamine vapours. Plasma Processes and Polymers 51(4): S781-S783.

9. Bryjak M, Gancarz I and Poniak G (1999) Surface evaluation of plasma-modified polysulfone (Udel P-1700) films. Langmuir 15(19): 6400-6404.

10. Akdoğan E and Mutlu M (2011) Generation of amphoteric surfaces via glow-discharge technique with single precursor and the behavior of bovine serum albumin at the surface. Colloids and Surfaces B: Biointerfaces 89: 289-294.

11. Ratner B (2004) Biomaterials Science: an Introduction to Materials in Medicine. Elsevier Academic Press, London, UK.

12. Henstock J, Canham L and Anderson S (2015) Silicon: the evolution of its use in biomaterials. Acta Biomaterialia 11: 17-26.

13. Bartzoka V, McDermott M and Brook M (1999) Protein-silicone interactions. Advanced Materials 11(3): 257-259.

14. Mark J (1998) Overview of siloxane polymers. Polymer Preprints (American Chemical Society, Division of Polymer Chemistry) $\mathbf{7 2 9}$ : 437-438.

15. Yamaguchi T, Nakao S and Kimura S (1991) Plasma-graft filling polymerization: preparation of a new type of pervaporation membrane for organic liquid mixtures. Macromolecules 24(20): 5522-5527.

16. Horbett TA, Ertel SI and Ratner BD (1990) Radio frequency plasma deposition of oxygen containing films on polystyrene and poly (ethylene terephthalate) substrates improves endothelial cell growth. Journal of Biomedical Materials Research 24(12): 1637-1659.

17. Akdoğan E (2010) Prevention of Bacterial Colonisation. Bioengineering Department, Institute for Pure and Applied Sciences, Hacettepe University, Ankara, Turkey. 
18. Fowkes FM, Kaczinski MB and Dwight DW (1991) Characterization of polymer surface sites with contact angles of test solutions: 1. phenol and iodine adsorption from methylene iodide onto PMMA films. Langmuir 7(11): 2464-2470.

19. Güleç HA, Sarıoglu K and Mutlu M (2006) Modification of food contacting surfaces by plasma polymerisation technique - part I: determination of hydrophilicity, hydrophobicity and surface free energy by contact angle method. Journal of Food Engineering 75(2): 187-195

20. Owen MJ and Dvornic PR (2012) Silicone Surface Science. Springer, Dordrecht, the Netherlands.

21. Abrosimova K, Shulenina O and Paston S (2016) FTIR study of secondary structure of bovine serum albumin and ovalbumin. Journal of Physics: Conference Series 769(1): 012016

22. Stuart B (2004) Infrared Spectroscopy: Fundamentals and Applications. Wiley, Weinheim, Germany.

23. Murayama K and Tomida M (2004) Heat-induced secondary structure and conformation change of bovine serum albumin investigated by Fourier transform infrared spectroscopy. Biochemistry 43(36): 11526-11532.

24. Roach P, Farrar D and Perry CC (2005) Interpretation of protein adsorption: surface-induced conformational changes. Journal of the American Chemical Society 127(22): 8168-8173.

25. Stuart B (2000) Infrared spectroscopy. In Kirk-Othmer Encyclopedia of Chemical Technology (Ley C (ed.)). Wiley, Hoboken, NJ, USA.

26. Schrader B (ed.) (2008) Infrared and Raman Spectroscopy: Methods and Applications. VCH, Weinheim, Germany.

27. Kato K, Matsui T and Tanaka S (1987) Quantitative estimation of $\alpha$-helix coil content in bovine serum albumin by Fourier transforminfrared spectroscopy. Applied Spectroscopy 41(5): 861-865.

28. You E, Jang H, Ahn W et al. (2007) In vitro biocompatibility of surface-modified poly(DL-lactide-co-glycolide) scaffolds with hydrophilic monomers. Journal of Industrial and Engineering Chemistry 13(2): 219-224.

29. Zange R, Li Y and Kissel T (1998) Biocompatibility testing of ABA triblock copolymers consisting of poly(L-lactic-co-glycolic acid) A blocks attached to a central poly(ethylene oxide) B block under in vitro conditions using different L929 mouse fibroblasts cell culture models. Journal of Controlled Release 56(1-3): 249-258.

30. Etienne J, Charpin B, Grando J et al. (1991) Characterization of clinically significant isolates of Staphylococcus epidermidis from patients with cerebrospinal fluid shunt infections. Epidemiology and Infection 106(3): 467-475.

31. Şen Y, Bağcı U, Güleç H and Mutlu M (2009) Modification of foodcontacting surfaces by plasma polymerization technique: reducing the biofouling of microorganisms on stainless steel surface. Food and Bioprocess Technology 5(1): 166-175.

32. Earnshaw J (2000) The current role of rifampicin-impregnated grafts: pragmatism versus science. European Journal of Vascular and Endovascular Surgery 20(5): 409-412.

33. Gulec HA, Topacli A, Topacli C, Albayrak N and Mutlu M (2010) Modification of cellulose acetate membrane via low-pressure plasma polymerization for sugar separation applications: part I membrane development and characterization. Journal of Membrane Science 350(1-2): 310-321.

34. Siow KS, Britcher L, Sunil K and Griesser HJ (2006) Characterization of sulfate and phosphate containing plasma polymer surfaces. Proceedings of the 2006 International Conference on Nanoscience and Nanotechnology, Brisbane, Australia.

35. Schrader B (ed.) (1995) Infrared and Raman Spectroscopy: Methods and Applications. VCH, New York, NY, USA.

36. Streuli CA (1960) Determination of basicity of substituted phosphines by nonaqueous titrimetry. Analytical Chemistry 32(8): 985-987.

37. Bhatt S, Pulpytel J, Ceccone G et al. (2011) Nanostructure protein repellant amphiphilic copolymer coatings with optimized surface energy by inductively excited low pressure plasma. Langmuir 27(23): 14570-14580.

38. Siow KS, Britcher L, Kumar S and Griesser HJ (2014) Deposition and XPS and FTIR analysis of plasma polymer coatings containing phosphorus. Plasma Processes and Polymers 11(2): 133-141.

39. Chittur KK (1998) FTIR/ATR for protein adsorption to biomaterial surfaces. Biomaterials 19(4-5): 357-369.

40. Giacomelli CE, Bremer MGEG and Norde W (1999) ATR-FTIR study of IGG adsorbed on different silica surfaces. Journal of Colloid and Interface Science 220(1): 13-23.

41. Holtz JSW, Holtz JH, Chi Z and Asher SA (1999) Ultraviolet Raman examination of the environmental dependence of bombolitin I and bombolitin III secondary structure. Biophysical Journal 76(6): 3227-3234.

42. Kato K, Matsui T and Tanaka S (1987) Quantitative estimation of $\alpha$-helix coil content in bovine serum albumin by Fourier transforminfrared spectroscopy. Applied Spectroscopy 41(5): 861-865.

43. Kolobow T, Stool E, Weathersby P et al. (1974) Superior blood compatibility of silicone rubber free of silica filler in the membrane lung. Transactions - American Society for Artificial Internal Organs 20A: 269-276.

44. An $Y$ and Friedman $R$ (1998) Concise review of mechanisms of bacterial adhesion to biomaterial surfaces. Journal of Biomedical Materials Research Part B: Applied Biomaterials 43(3): 338-348.

45. Geesey GG (2001) Bacterial behavior at surfaces. Current Opinion in Microbiology 4(3): 296-300.

46. Sutherland I (2001) Biofilm exopolysaccharides: a strong and sticky framework. Microbiology 147(1): 3-9.

47. Heumann D and Roger T (2002) Initial responses to endotoxins and gram-negative bacteria. Clinica Chimica Acta 323(1-2): 59-72.

48. Al-Tahhan R, Sandrin T, Bodour A and Maier R (2000) Rhamnolipidinduced removal of lipopolysaccharide from Pseudomonas aeruginosa: effect on cell surface properties and interaction with hydrophobic substrates. Applied and Environmental Microbiology 66(8): 3262-3268.

49. Wei J, Ravn D, Gram L and Kingshott P (2003) Stainless steel modified with poly(ethylene glycol) can prevent protein adsorption but not bacterial adhesion. Colloids and Surfaces B: Biointerfaces 32(4): 275-291.

50. Kockro R, Hampl J, Jansen B et al. (2000) Use of scanning electron microscopy to investigate the prophylactic efficacy of rifampinimpregnated CSF shunt catheters. Journal of Medical Microbiology 49(5): 441-450.

51. Kenawy ER, Worley S and Broughton R (2007) The chemistry and applications of antimicrobial polymers: a state-of-the-art review. Biomacromolecules 8(5): 1359-1384.

52. Cloutier M, Mantovani D and Rosei F (2015) Antibacterial coatings: challenges, perspectives, and opportunities. Trends in Biotechnology 33(11): 637-652.

53. Ayhan F and Özkan S (2007) Gentamicin release from photopolymerized PEG diacrylate and pHEMA hydrogel discs and their in vitro antimicrobial activities. Drug Delivery 14(7): 433-439.

54. Çakır CO, Ozturk M and Tuzlakoğlu K (2018) Design of antibacterial bilayered silk fibroin-based scaffolds for healing of severe skin damages. Materials Technology 33(10): 651-658.

55. Zhang X, Wang L and Levänen E (2013) Superhydrophobic surfaces for the reduction of bacterial adhesion. RSC Advances 3(30): 12003-12020

56. Bhatt S, Pulpytel J and Arefi-Khonsari F (2015) Low and atmospheric plasma polymerisation of nanocoatings for bio-applications. Surface Innovation 3(2): 63-83.

57. Yu Q, Wu Z and Chen H (2015) Dual-function antibacterial surfaces for biomedical applications. Acta Biomaterialia 16: 1-13.

58. Junter GA, Thébault P and Lebrun L (2016) Polysaccharide-based antibiofilm surfaces. Acta Biomaterialia 30: 13-25. 
59. Karakeçili AG and Gümüşderelioğlu M (2002) Comparison of bacterial and tissue cell initial adhesion on hydrophilic/hydrophobic biomaterials. Journal of Biomaterials Science, Polymer Edition 13(2) 185-196.

60. Bassler BL (1999) How bacteria talk to each other: regulation of gene expression by quorum sensing. Current Opinion in Microbiology 2(6) 582-587.

61. De Nys R, Givskov M, Kumar N, Kjelleberg S and Steinberg P (2006) Furanones. In Antifouling Compounds (Fusetani N and Clare AS (eds)). Springer, Berlin, Germany, pp. 55-86

62. Hume E, Baveja J, Muir B et al. (2004) The control of Staphylococcus epidermidis biofilm formation and in-vivo infection rates by covalently bound furanones. Biomaterials 25(20): 5023-5030.

63. Aydogan DT, Muhaffel F, Acar OK et al. (2018) Surface modification of Ti6Al4V by micro-arc oxidation in $\mathrm{AgC}_{2} \mathrm{H}_{3} \mathrm{O}_{2}$ containing electrolyte. Surface Innovations 6(4-5): 277-285.

64. Vogel K, Westphal N, Salz D et al. (2015) Dental implants coated with a durable and antibacterial film. Surface Innovations 3(1): 27-38.

65. Teker Aydogan D, Muhaffel F, Kilic M et al. (2018) Optimisation of micro-arc oxidation electrolyte for fabrication of antibacterial coating on titanium. Materials Technology 33(2): 119-126.

66. Poussard L, Ouedraogo C, Pavon-Djavid G and Migonney V (2012) Inhibition of Staphylococcus epidermidis adhesion on titanium surface with bioactive water-soluble copolymers bearing sulfonate, phosphate or carboxylate functions. Pathologie Biologie 60(2): 84-90.

67. Sin MC, Sun YM and Chang Y (2014) Zwitterionic-based stainless steel with well-defined polysulfobetaine brushes for general bioadhesive control. ACS Applied Materials \& Interfaces 6(2): 861-873.

68. Vasilev K, Sah VR, Goreham RV et al. (2010) Antibacterial surfaces by adsorptive binding of polyvinyl-sulphonate-stabilized silver nanoparticles. Nanotechnology 21(21): 215102.

69. Lau KHA, Ren C, Sileika TS et al. (2012) Surface-grafted polysarcosine as a peptoid antifouling polymer brush. Langmuir $\mathbf{2 8 ( 4 6 )}$ 16099-16107.

70. Guo S, Jańczewski D, Zhu X et al. (2015) Surface charge control for zwitterionic polymer brushes: tailoring surface properties to antifouling applications. Journal of Colloid and Interface Science 452: 43-53.

71. Yang F, Liu Y, Zhang $Y$ et al. (2017) Synthesis and characterization of ultralow fouling poly( $N$-acryloyl-glycinamide) brushes. Langmuir 33(49): 13964-13972.

72. Treter J, Bonatto F, Krug C et al. (2014) Washing-resistant surfactant coated surface is able to inhibit pathogenic bacteria adhesion. Applied Surface Science 303: 147-154.

73. Cheng G, Zhang Z, Chen S, Bryers JD and Jiang S (2007) Inhibition of bacterial adhesion and biofilm formation on zwitterionic surfaces. Biomaterials 28(29): 4192-4199.

74. Ajithkumar M, Yashoda M, Prasannakumar S, Sruth T and Sameer Kumar V (2017) Poly( $N$-vinyl-2-pyrrolidone-maleic anhydridestyrene) grafted terpolymer: synthesis, characterization, and bactericidal property evaluation against $E$. coli and $S$. epidermidis. Journal of Macromolecular Science, Part A 54(7): 480-488.

75. Morra M and Cassineli C (1999) Non-fouling properties of polysaccharide-coated surfaces. Journal of Biomaterials Science, Polymer Edition 10(10): 1107-1124.

76. Bernards M and $\mathrm{He} \mathrm{Y} \mathrm{(2014)} \mathrm{Polyampholyte} \mathrm{polymers} \mathrm{as} \mathrm{a} \mathrm{versatile}$ zwitterionic biomaterial platform. Journal of Biomaterials Science, Polymer Edition 25(14-15): 1479-1488.

77. Mi L, Bernards MT, Cheng G, Yu Q and Jiang S (2010) pH responsive properties of non-fouling mixed-charge polymer brushes based on quaternary amine and carboxylic acid monomers. Biomaterials 31(10): 2919-2925.

78. Smith RS, Zhang Z, Bouchard M et al. (2012) Vascular catheters with a nonleaching poly-sulfobetaine surface modification reduce thrombus formation and microbial attachment. Science Translational Medicine 4(153): 153 ra132.

79. Balaban N, Giacometti A, Cirioni O et al. (2003) Use of the quorumsensing inhibitor RNAIII-inhibiting peptide to prevent biofilm formation in-vivo by drug-resistant Staphylococcus epidermidis. Journal of Infectious Diseases 187(4): 625-630.

80. Gottenbos B, van der Mei HC, Klatter F, Nieuwenhuis P and Busscher HJ (2002) In-vitro and in-vivo antimicrobial activity of covalently coupled quaternary ammonium silane coatings on silicone rubber. Biomaterials 23(6): 1417-1423.

81. Nablo BJ, Prichard HL, Butler RD, Klitzman B and Schoenfisch MH (2005) Inhibition of implant-associated infections via nitric oxide release. Biomaterials 26(34): 6984-6990.

82. Weintraub S, Harris LG, Thevissen K and Lewitus DY (2018) Polyastaxanthin-based coatings reduce bacterial colonization in-vivo. Materialia 3: 15-20.

83. Chen M, Yu Q and Sun H (2013) Novel strategies for the prevention and treatment of biofilm related infections. International Journal of Molecular Sciences 14(9): 18488-18501.

84. Gulec HA, Sarıoglu K and Mutlu M (2006) Modification of food contacting surfaces by plasma polymerisation technique - part I: determination of hydrophilicity, hydrophobicity and surface free energy by contact angle method. Journal of Food Engineering 75(2) 187-195.

85. Mutlu S, Çökeliler D and Mutlu M (2007) Modification of food contacting surfaces by plasma polymerization technique - part II: static and dynamic adsorption behavior of a model protein 'bovine serum albumin' on stainless steel surface. Journal of Food Engineering 78(2): 494-499.

86. Baier RE (1973) Influence of the initial surface condition of materials on bioadhesion. In Proceedings of Conference on Third International Congress on Marine Corrosion and Fouling (Acker RF, Floyd Brown B, De Palma JR and Iverson WP (eds)). Northwestern University Press, Evanston, IL, USA, pp. 633-639.

87. Yang R, Moni P and Gleason KK (2015) Ultrathin zwitterionic coatings for roughness independent underwater superoleophobicity and gravity driven oil water separation. Advanced Materials Interfaces 2(2): 1400489.

88. Georgiev GS, Kamenska EB, Vassileva ED et al. (2006) Self-assembly, antipolyelectrolyte effect, and nonbiofouling properties of polyzwitterions. Biomacromolecules 7(4): 1329-1334.

89. Busscher HJ, van der Mei HC, Subbiahdoss G et al. (2012) Biomaterial-associated infection: locating the finish line in the race for the surface. Science Translational Medicine 4(153): 153 rv110.

\section{How can you contribute?}

To discuss this paper, please submit up to 500 words to the journal office at journals@ice.org.uk. Your contribution will be forwarded to the author(s) for a reply and, if considered appropriate by the editor-in-chief, it will be published as a discussion in a future issue of the journal.

ICE Science journals rely entirely on contributions from the field of materials science and engineering. Information about how to submit your paper online is available at www.icevirtuallibrary.com/page/authors, where you will also find detailed author guidelines 